\title{
Skin Prick Test Reactivity to Aeroallergens in Allergic Rhinitis Children in Guangzhou, Southern China
}

\author{
Jie Zhong ${ }^{*}$, Da-Bo Liu, Zhen-Yun Huang and Jian-Wen Zhong
}

Department of Otolaryngology, Guangzhou Women and Children's Medical Center, Guangzhou Children's Hospital, China

*Corresponding author: Jie Zhong, Department of Otolaryngology, Guangzhou Women and Children's Medical Center, Guangzhou Children's Hospital, 318\# Ren Min Zhong Road, Yue Xiu District, Guangzhou, 510120, China, Tel: 86-20-81330660/86-13580334477; E-mail:17902969@qq.com

Rec date: May 05, 2014, Acc date: May 30, 2014, Pub date: June 05, 2014

Copyright: (c) 2014 Zhong J, et al. This is an open-access article distributed under the terms of the Creative Commons Attribution License, which permits unrestricted use, distribution, and reproduction in any medium, provided the original author and source are credited.

\begin{abstract}
This retrospective study reviewed skin prick test (SPT) positive results to various aeroallergens among 2136 children with allergic rhinitis (AR) in Guangzhou City, Southern China. Most (74.67\%) of the 2136 children who underwent skin test showed positive reaction to 2-4 allergens. The allergen group with the highest positive incidence was Dermatophagoides pteronyssinus (der.p.) at $93.16 \%$, followed by Dermatophagoides farinae (der.f.) at $86.23 \%$, Tropical mites at $40.73 \%$, Cat hair at $20.32 \%$ and Blattella germanica at $19.62 \%$. Dust mites (der.p. \& der.f) yielded strong positive reaction trend on AR children. The positive rate of der.p.,Cat hair and Blattella germanica was higher in school children group than preschool children group. Except for Blattella germanica, sensitization to every tested allergen varied in four season groups. These allergens should be given the highest priority when making the allergen avoidance strategies for AR children.
\end{abstract}

Keywords: Allergic rhinitis; Dermatophagoides pteronyssinus; Allergen; Specific immune therapy

\section{Introduction}

Allergic Rhinitis (AR) is one of the common chronic diseases in children and with an increase in the incidence during the past 10 years. The onset of AR is usually in childhood or adolescence. It is a nasal mucosa chronic inflammatory disease which gets involved with multiple immunologically competent cells and cell factor. When atopic individuals are exposed to the allergens, the medium (mainly histamines) mediated by IgE will be released and cause the AR Symptoms.

In China, the general incidence of $\mathrm{AR}$ is $10 \%$ and up to $11 \%$ among children aged 3-6 years, which reach the peak at $13 \%$ in Guangzhou City [1-3]. According to the diagnostic standard proposed on the Chongqing Conference 2010, China [4], the positive reaction to allergens is one of the necessary bases for confirming the diagnosis of AR.

Acquiring the allergen status of AR individuals is meaningful on the guidance for patients to avoid relevant allergens. And it can also provide an exact basis on the specific immune therapy (SIT). Skin prick test is a common diagnostic tool to determine specific allergen in vivo, which requires few supplies and has become relatively standardized in its application. Furthermore, it is also cost-efficient and has a high degree of adaptability from children.

Only half an hour for testing, the allergic state on the case can be obtained. The distribution of allergens varied in different regions due to the variety of geographic and meteorological conditions. This study was conducted to investigate the prevalence of skin test positivity to 11 aeroallergens among AR children in Guangzhou City, Southern China.

\section{Materials and Methods}

\section{The allergens}

The inhalant allergen panels used were obtained from Allergo Pharma, Germany. The extracts of 11 different aeroallergens included house dust mites (Dermatophagoides pteronyssinus [der.p.] and Dermatophagoides farinae [der.f.]), Tropical mites, epithelia and insect allergens (Dog hair, Cat hair and Blattella germanica), Alternaria tenuis, outdoor allergens(Artemisia argyi, Ragweed, Timothy grass and Birch).

\section{Skin prick test}

Skin prick tests were carried out on all the 2136 subjects and performed on the ventral side of the forearm. One drop (0.01 ml-0.02 $\mathrm{ml}$ ) of the standardized allergen extracts were applied in a parallel array to the axis of forearm two centimeters apart after cleaning the skin with alcohol. Histamine solution $(10 \mathrm{mg} / \mathrm{ml})$ was used as positive control, while saline solution used as negative control. The reaction was read after 15-20 minutes. The size of wheal was determined by measuring the mean of the longest diameter and vertical diameter to it. Similarly, the size of histamine wheal was worked out. The contrast of these two diameters was Skin Index (SI). When the wheal's diameter was the same as that of negative control, it was recorded as (-).The results were read as " + " with $\mathrm{SI} \leq 0.5$, " ++ " with $0.5<$ SI $\leq 1.0$, " +++ " with $1.0<$ SI $\leq 2.0$, “++++" with SI $>2.0$, respectively [6]. Meanwhile, "+ ++ " and " ++++ " meant strong positive.

\section{General climate of Guangzhou}

Guangzhou is situated at $23^{\circ} 16^{\prime} \mathrm{N} / 113^{\circ} 23^{\prime} \mathrm{E}$ in the south of China, which has a subtropical monsoon climate. The annual average temperature was $21.9^{\circ} \mathrm{C}$ in 2013 and the relative humidity was always more than $55 \%$ in the year. The meteorological data for Guangzhou were obtained from Guangdong meteorological Administration. 
Citation: Zhong J, Liu DB, Huang ZY, Zhong JW (2014) Skin Prick Test Reactivity to Aeroallergens in Allergic Rhinitis Children in Guangzhou,

Page 2 of 6

\section{Statistical analysis}

Data were analyzed by using the Statistical Package for Social Sciences (SPSS) software, version 13.0. The positive rate among various groups was analyzed with Chi-square tests. A p-value $<0.05$ was deemed statistically significant.

\section{Statistical analysis}

Data were analyzed by using the Statistical Package for Social Sciences (SPSS) software, version 13.0. The positive rate among various groups was analyzed with Chi-square tests. A p-value $<0.05$ was deemed statistically significant.

\section{Results}

During the study period 2136 AR children demonstrated allergic sensitization by the mean of skin prick test. 1573 (73.64\%) of the sample patients were boys, while $563(26.36 \%)$ were girls. Their ages ranged from 3 years to 16 years (mean $\pm \mathrm{SD}, 7.59 \pm 2.48$ years). According to age these cases were divided into school children group

( $\geq 7$ years old) and preschool children group ( $<7$ years old), which were also divided into 4 season groups according to attendance time :spring (March to May), summer (June to August), autumn (September to November) and winter (December to February).while divided into season groups, we found spring 478 cases $(22.38 \%)$, summer 1066 cases (49.91\%), autumn 203 cases (9.50\%) and winter 389 cases (18.21\%) (Figure 1).

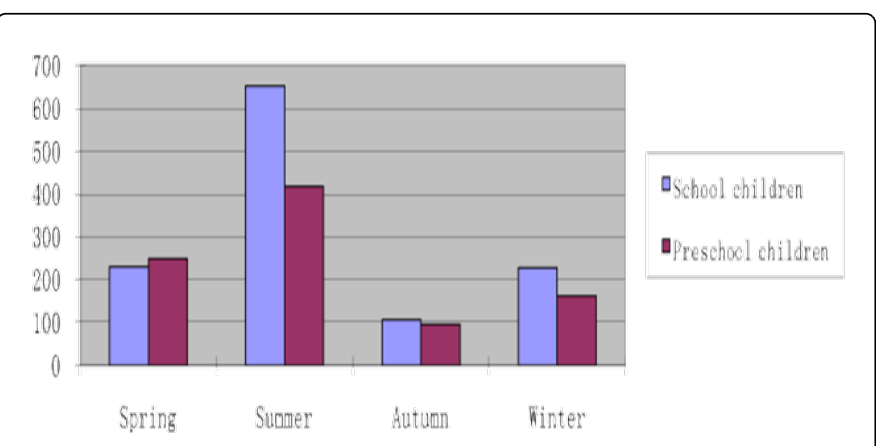

Figure 1: Case Distribution of Age Group in Seasons (cases)

There were 1595 cases $(74.67 \%)$ with a positive SPT to $2-4$ allergens, followed by 345 cases (16.15\%) to at least 5 allergens and 196 children (9.18\%) to only one allergen. It was observed that most of the AR children were sensitized to 2-4 allergens, while the cases allergic to a single and five or more allergens were in low proportion (Figure 2).

Dust mites were the most common allergen causing skin test reactions. The positive rate of Dust mites (der.p and der.f) was statistically significantly higher than other allergens $(\mathrm{P}<0.05)$. According to the positive frequency distribution of the specific aeroallergens, the top five aeroallergens were der.p. (93.16\%), der.f. (86.23\%), Tropical mites (40.73\%), Cat hair (20.32\%) and Blattella germanica $(19.62 \%)$. And sensitization to outdoor allergens were the least common (Table 1).

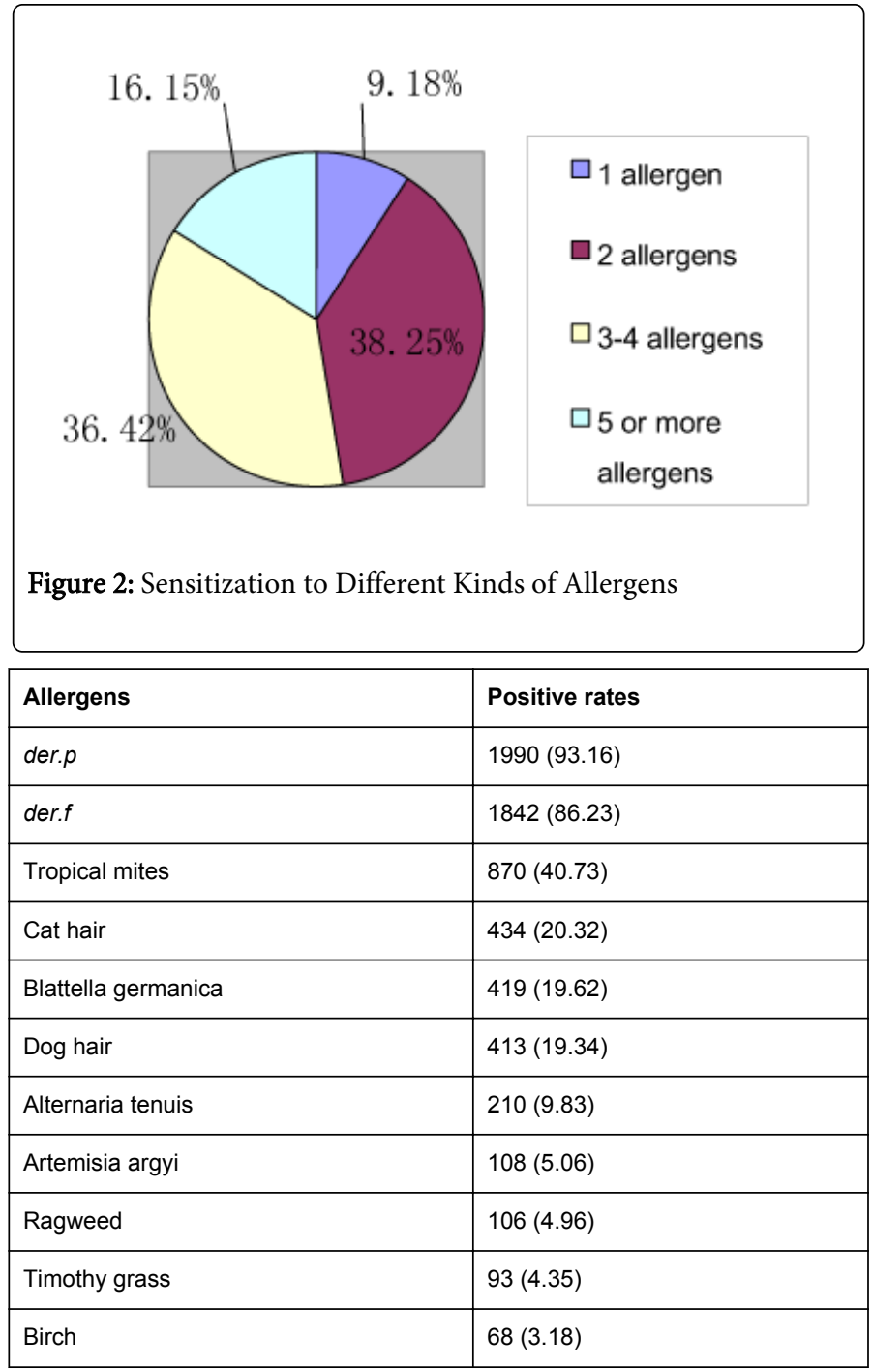

Table 1: Positive Rates of 11 aeroallergens [cases, percentage (\%)]

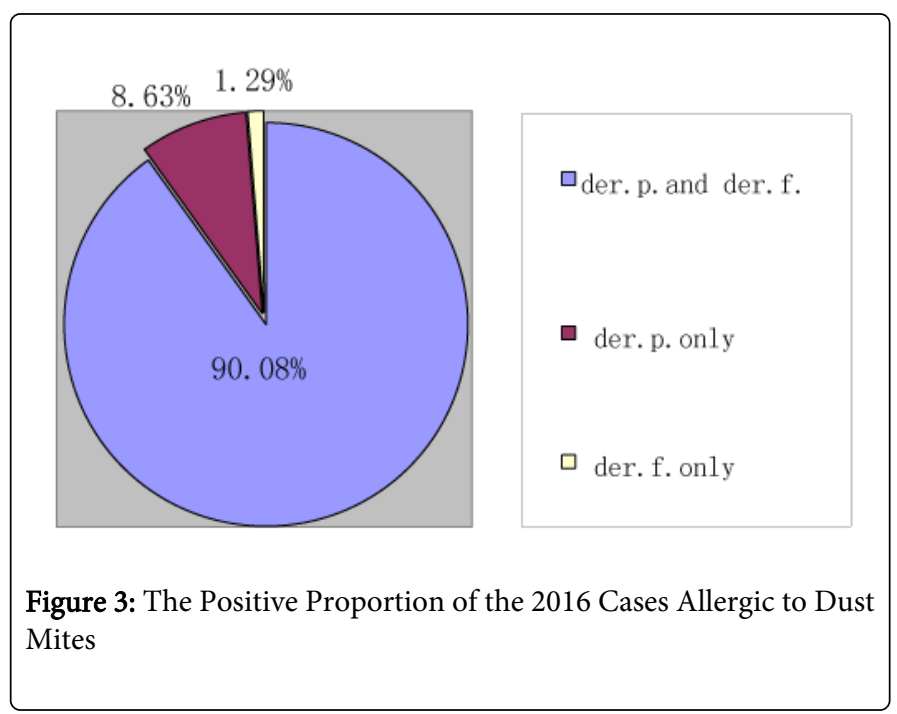


Citation: Zhong J, Liu DB, Huang ZY, Zhong JW (2014) Skin Prick Test Reactivity to Aeroallergens in Allergic Rhinitis Children in Guangzhou,

Page 3 of 6

There were only 153 cases reactive to such outdoor allergens as Artemisia argyi, Ragweed, Timothy grass and Birch (108 cases, 106 cases, 93 cases, and 68 cases, respectively). Among the 2016 children allergic to dust mites (der.p or der.f.), there were 1816 (90.08\%) cases that showed positive reaction to both der.p and der.f, while 174 (8.63\%) subjects to der.p. only and $26(1.29 \%)$ patients to der.f. only (Figure 3).

Furthermore, it was 1676 children who showed strong reaction ("+ ++ " and " ++++ ") to dust mites and there was no statistical significance on the strong positive rate of dust mites in any season between age groups (Table 2).

\begin{tabular}{|l|l|l|l|l|l|l|}
\hline Season & \multicolumn{2}{|l|}{ School Children } & \multicolumn{2}{l|}{ Pre-school Children } & $\mathbf{X}^{2}$ & $\mathbf{P}$ \\
\hline & Positive & $\begin{array}{l}\text { Strong } \\
\text { positive }\end{array}$ & Positive & $\begin{array}{l}\text { Strong } \\
\text { positive }\end{array}$ & & \\
\hline Spring & 209 & $\begin{array}{l}170 \\
(81.34)\end{array}$ & 235 & $\begin{array}{l}191 \\
(81.28)\end{array}$ & 0 & $P>0.05$ \\
\hline \multirow{2}{*}{ Summer } & 640 & $\begin{array}{l}541 \\
(84.53)\end{array}$ & 393 & $\begin{array}{l}320 \\
(81.42)\end{array}$ & 1.69 & $P>0.05$ \\
\hline \multirow{2}{*}{ Autumn } & 102 & $\begin{array}{l}84 \\
(82.35)\end{array}$ & 92 & $\begin{array}{l}74 \\
(80.43)\end{array}$ & 0.18 & $P>0.05$ \\
\hline \multirow{2}{*}{ Winter } & 208 & $\begin{array}{l}182 \\
(87.50)\end{array}$ & 137 & $\begin{array}{l}114 \\
(83.21)\end{array}$ & 1.25 & $P>0.05$ \\
\hline
\end{tabular}

Table 2: Comparison on Strong Positivity of Dust Mites in Seasons between Age Groups [cases, percentage (\%)]

It was observed that the positive rates of der.p, Cat hair and Blattella germanica were statistically significantly higher in school children group in comparison to preschool children group $(\mathrm{P}<0.05)$. Nevertheless, there was no difference on the positive rate of any other 8 allergens between the two groups (Figure 4 and Table 3).

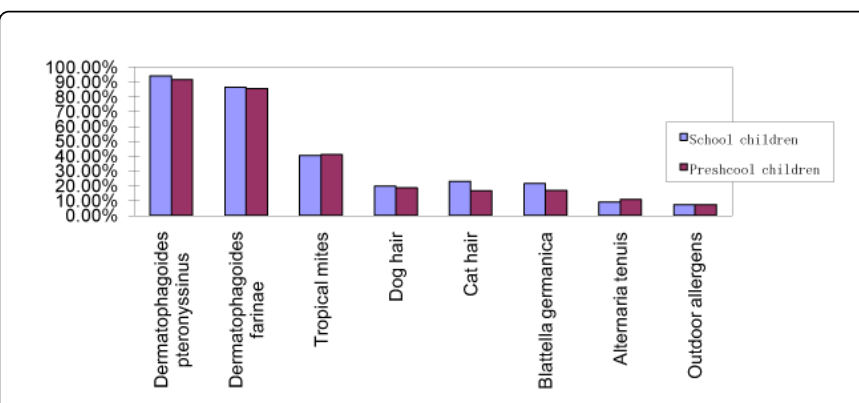

Figure 4: Distribution of Allergens Positive Rate between Age Groups

Except for Blattella germanica sensitization to each tested allergens was statistically significantly different in four season groups (Figure 5 and Table 4). The positive rate of both der.p and der.f turned out to be the lowest in winter and almost the same in the rest seasons. It was Alternaria tenuis and the 4 outdoor allergens that showed a high lever on the positive reaction in both autumn and winter (Tropical mites in autumn, Dog hair and Cat hair in winter, respectively). Anyhow, allergic reaction to Tropical mites, Dog hair, Cat hair, Alternaria tenuis and the 4 outdoor allergens all was the least common in summer.

\begin{tabular}{|l|l|l|l|l|l|}
\hline Allergens & $\begin{array}{l}\text { Positive } \\
\text { Cases } \\
(\mathbf{n = 2 1 3 6 )}\end{array}$ & $\begin{array}{l}\text { School } \\
\text { Children } \\
(\mathbf{n = 1 2 1 4 )}\end{array}$ & $\begin{array}{l}\text { Preschool } \\
\text { Children } \\
(\mathbf{n}=\mathbf{9 2 2})\end{array}$ & $\mathrm{X}^{2}$ & $\mathbf{P}$ \\
\hline der.p, & $\begin{array}{l}1990 \\
(93.16)\end{array}$ & $\begin{array}{l}1144 \\
(94.23)\end{array}$ & $\begin{array}{l}846 \\
(91.76)\end{array}$ & 5.05 & $\mathrm{P}<0.05$ \\
\hline der.f & $\begin{array}{l}1842 \\
(86.23)\end{array}$ & $\begin{array}{l}1052 \\
(86.66)\end{array}$ & $\begin{array}{l}790 \\
(85.68)\end{array}$ & 0.42 & $\mathrm{P}>0.05$ \\
\hline Tropical mites & $\begin{array}{l}870 \\
(40.73)\end{array}$ & $\begin{array}{l}492 \\
(40.53)\end{array}$ & $\begin{array}{l}378 \\
(41.00)\end{array}$ & 0.05 & $\mathrm{P}>0.05$ \\
\hline Dog hair & $\begin{array}{l}413 \\
(19.34)\end{array}$ & $\begin{array}{l}240 \\
(19.77)\end{array}$ & $\begin{array}{l}173 \\
(18.76)\end{array}$ & 0.34 & $\mathrm{P}>0.05$ \\
\hline Cat hair & $\begin{array}{l}434 \\
(20.32)\end{array}$ & $\begin{array}{l}281 \\
(23.15)\end{array}$ & $\begin{array}{l}153 \\
(16.59)\end{array}$ & 13.89 & $\mathrm{P}<0.05$ \\
\hline $\begin{array}{l}\text { Blattella } \\
\text { germanica }\end{array}$ & $\begin{array}{l}419 \\
(19.62)\end{array}$ & $\begin{array}{l}263 \\
(21.66)\end{array}$ & $\begin{array}{l}156 \\
(16.92)\end{array}$ & 7.48 & $\mathrm{P}<0.05$ \\
\hline Alternaria tenuis & $\begin{array}{l}210 \\
(9.83)\end{array}$ & $\begin{array}{l}110 \\
(9.06)\end{array}$ & $\begin{array}{l}100 \\
(10.85)\end{array}$ & 1.88 & $\mathrm{P}>0.05$ \\
\hline $\begin{array}{l}\text { Outdoor } \\
\text { allergens }\end{array}$ & $\begin{array}{l}153 \\
(7.16)\end{array}$ & $\begin{array}{l}87 \\
(7.17)\end{array}$ & $\begin{array}{l}66 \\
(7.16)\end{array}$ & 0 & $\mathrm{P}>0.05$ \\
\hline
\end{tabular}

Table 3: Comparison on Allergens Positive rate between Age Groups [cases, percentage (\%)]

\begin{tabular}{|l|l|l|l|l|l|l|l|}
\hline $\begin{array}{l}\text { Allergen } \\
\mathbf{s}\end{array}$ & $\begin{array}{l}\text { Positive } \\
\text { Cases } \\
(\mathbf{n = 2 1 3 6 )}\end{array}$ & $\begin{array}{l}\text { Spring } \\
(\mathbf{n}=\mathbf{4 7 8})\end{array}$ & $\begin{array}{l}\text { Summe } \\
\mathbf{r} \\
(\mathbf{n = 1 0 6} \\
\mathbf{6})\end{array}$ & $\begin{array}{l}\text { Autum } \\
\mathbf{n} \\
(\mathbf{n = 2 0 3 )}\end{array}$ & $\begin{array}{l}\text { Winter } \\
(\mathbf{n = 3 8 9 )}\end{array}$ & $\mathbf{X}^{2}$ & $P$ \\
\hline der.p, & 1990 & $\begin{array}{l}439 \\
(91.84)\end{array}$ & $\begin{array}{l}1020 \\
(95.68)\end{array}$ & $\begin{array}{l}191 \\
(94.09)\end{array}$ & $\begin{array}{l}340 \\
(87.40)\end{array}$ & 32.49 & $\begin{array}{l}P<0.0 \\
5\end{array}$ \\
\hline der.f. & 1842 & $\begin{array}{l}426 \\
(89.12)\end{array}$ & $\begin{array}{l}951 \\
(89.21)\end{array}$ & $\begin{array}{l}177 \\
(87.19)\end{array}$ & $\begin{array}{l}288 \\
(74.04)\end{array}$ & 60.24 & $\begin{array}{l}P<0.0 \\
5\end{array}$ \\
\hline $\begin{array}{l}\text { Tropical } \\
\text { mites }\end{array}$ & 870 & $\begin{array}{l}278 \\
(58.16)\end{array}$ & $\begin{array}{l}263 \\
(24.67)\end{array}$ & $\begin{array}{l}126 \\
(62.07)\end{array}$ & $\begin{array}{l}203 \\
(52.19)\end{array}$ & $\begin{array}{l}233.4 \\
5\end{array}$ & $\begin{array}{l}P<0.0 \\
5\end{array}$ \\
\hline Dog hair & 413 & $\begin{array}{l}149 \\
(31.17)\end{array}$ & $\begin{array}{l}74 \\
(6.94)\end{array}$ & $\begin{array}{l}51 \\
(25.12)\end{array}$ & $\begin{array}{l}139 \\
(35.73)\end{array}$ & $\begin{array}{l}219.3 \\
4\end{array}$ & $\begin{array}{l}P<0.0 \\
5\end{array}$ \\
\hline Cat hair & 434 & $\begin{array}{l}88 \\
(18.41)\end{array}$ & $\begin{array}{l}157 \\
(14.73)\end{array}$ & $\begin{array}{l}56 \\
(27.59)\end{array}$ & $\begin{array}{l}133 \\
(34.19)\end{array}$ & 74.51 & $\begin{array}{l}P<0.0 \\
5\end{array}$ \\
\hline $\begin{array}{l}\text { Blattella } \\
\text { germanic } \\
\text { a }\end{array}$ & 419 & $\begin{array}{l}88 \\
(18.41)\end{array}$ & $\begin{array}{l}200 \\
(18.76)\end{array}$ & $\begin{array}{l}36 \\
(17.73)\end{array}$ & $\begin{array}{l}95 \\
(24.42)\end{array}$ & 7.09 & $\begin{array}{l}P<0.0 \\
5\end{array}$ \\
\hline $\begin{array}{l}\text { Alternaria } \\
\text { tenuis }\end{array}$ & 210 & $\begin{array}{l}57 \\
(11.92)\end{array}$ & $\begin{array}{l}60 \\
(5.63)\end{array}$ & $\begin{array}{l}32 \\
(15.76)\end{array}$ & $\begin{array}{l}61 \\
(15.68)\end{array}$ & 46.68 & $\begin{array}{l}P<0.0 \\
5\end{array}$ \\
\hline $\begin{array}{l}\text { Outdoor } \\
\text { allergens }\end{array}$ & 153 & $\begin{array}{l}40 \\
(8.37)\end{array}$ & $\begin{array}{l}43 \\
(4.03)\end{array}$ & $\begin{array}{l}24 \\
(11.82)\end{array}$ & $\begin{array}{l}46 \\
(11.83)\end{array}$ & 36.08 & $\begin{array}{l}P<0.0 \\
5\end{array}$ \\
\hline
\end{tabular}

Table 4: Comparison on Allergen Positive rate in Seasons Groups [cases, percentage (\%)] 


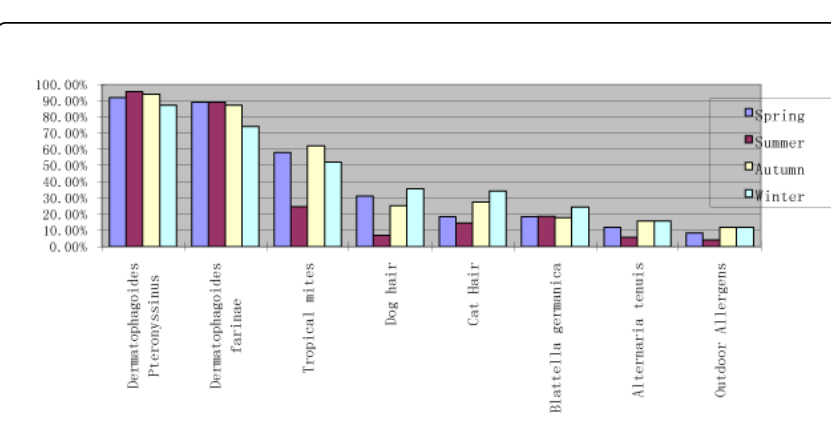

Figure 5: Positive Rates of Specific Allergens in Seasons

\section{Discussion}

This study reported on skin prick test reactivity to aeroallergens among AR children in Guangzhou city, Southern China. By far the sample patients have been the largest children population compared to previous studies performed in this region. Among the subjects, boys were much more than girls (boy: girl, 2.79:1). A similar finding conducted on children aged range from 3 to 6 years in Wuhan city, not too far away from Guangzhou, demonstrated that boys with AR were nearly twice more than girls [2]. It probably suggests that boys are more likely to present AR symptoms than girls. An investigation performed in Guangzhou indicated that the average dust content collected from girls' dormitory beds was much less than that of boys', and the average mites' quantity on boys' beds was much more than that of girls' [7], which was maybe the major cause of high prevalence in boys. Therefore, whether the hygienic habit of children and their parents contributed to the sexual differences in prevalence of $A R$ should be considered in the further study. We recommend further comprehensive research on this subject. In our study subjects attending ENT outpatient clinic in summer accounted for almost $1 / 2$ of the whole year sample in a year. It revealed that AR symptoms were more likely to present in summer. Previous investigations had shown that dust mites were the most important allergen for AR in China [8]. A report conducted on indoor conditions in Guangzhou pointed out that the der.f concentration level in summer was the highest all over the year [9]. Guangzhou is located in subtropical zone with hot and damp climate, where indoor air conditioning is highly used in summer. Firstly, the filter mesh of air conditioning is the ideal condition for the growth of dust mites [10]. Secondly, children would spend more time at home instead of school when summer holidays come, which could greatly increase the risk of being exposed to dust mites. Finally, the indoor cold air from air conditioning will stimulate the vascular of nasal mucosa and lead to allergic symptoms. That's why so many children go to see the ENT doctors in summer rather than other seasons.

The proportion of allergic patients reactive to at least 2 allergens in Guangzhou was $66.11 \%$ in 2011 [11]. Increasingly, there were $90.82 \%$ of the AR children sensitive to two or more allergens in this study. Maybe there were some causes contributing to the increasing prevalence of sensitization to allergens. Firstly, an investigation concerned on housing difficulties in Guangdong province showed that over the past few years more and more people had moved to Guangzhou to seek better future and lived with small humble abode, along with the high room rate led to less living space for most families there [12]. Secondly, excessive indoor decoration would increase the level of indoor air pollution and it became the risk for allergic disease in recent years [13]. Thirdly, with the rapid economic development the usage rate of air conditioning in Guangzhou was $85 \%$ in 2003, which reached $90.2 \%$ in 2010 [14,15]. In general the factors above probably result in bad air flows and a rise of allergen level indoor. Patients allergic to a single allergen took a proportion of only $9.18 \%$, and the cases sensitive to 5 or more allergens counted for $16.15 \%$. We could see that one allergen usually coexists with another or more allergens, and which cause symptoms and lead to synergistic reaction. The positive proportion of school children who were allergic to 5 or more allergens was higher than that of preschool children. It probably indicated that elder children were easier to be sensitized by multiple allergens. This may be due to the wider scope of activity and more chances to be exposed to more allergens as they grow up. Barnes pointed out that when a specific individual was kept in the environment of allergens for a long time, the specific IgE antibody reaction would be stimulated and accumulated in vivo, which lead to allergy symptoms [16]. Therefore, the high-susceptibility children should be educated to put on a mask outdoors in order to avoid more new allergens.

In this study the positive rate of der.p and der.f. was $93.16 \%$ and $86.23 \%$, respectively, which was much higher than other tested allergens. It revealed that dust mites were the main allergens for AR children in Guangzhou. These allergens should be given the highest priority when educating AR children regarding allergen avoidance strategies. In contrast, the positive frequency of dust mites was roughly 64.3\% in Beijing (Northern China) and 95\% in Changsha (Southern China), respectively $[17,18]$. We can conclude that allergic sensitization to dust mites in Southern China much more popular than that in Northern China due to the variations in geographic and meteorological conditions. As known the average annual temperature of Guangzhou is $21.9^{\circ} \mathrm{C}$, and the relative humidity there is always more than $55 \%$ in a year. Similarly, the favourable ambient temperature for dust mites is $25^{\circ} \mathrm{C}$ (relative humidity, $75 \%-80 \%$ ). Therefore, Guangzhou is really a suitable place for dust mites to grow. It was pointed out that indoor allergen in Guangzhou was always in high level ( $>10 \mu \mathrm{g} / \mathrm{g})$, which was a risk factor to cause acute allergy [9]. In our study the positive rate of Tropical mites was $40.73 \%$, while a similar finding showed the rate of allergic sensitization to Tropical mites on skin tests was $43 \%$ for the asthma and/or AR suffers in Guangzhou [19]. It indicated Tropical mites were also one of the important aeroallergens to AR children in this region. However, it was found no sign of activity for Tropical mites in the detection of indoor allergens there, which probably suggested the positive reaction to Tropical mites wasn't necessarily directly caused by themselves [9]. $90.08 \%$ of the 2016 subjects who were allergic to dust mites showed positive reaction to both der.p and der.f. The two mites showed great consistency in the positive rate in our study. There may be antigenic cross-reaction together with dust mites, which was supported by the fact that there were cross-reacting antigens among multiple mites by means of immune electrophoresis [20]. Therefore, the European WHO remands medical doctors to perform specific immune therapy with single allergen [21]. Meanwhile, 1676 (83.13\%) of the 2016 children showed strong positivity to dust mites. There was no statistical significance for the strong positive reaction among age groups and season groups. It suggested that dust mites lead to strong positive trend on AR children. Probably the early-stage specific immune therapy for a single mite probably fits much better with children than adults who are allergic to dust mites. 
Page 5 of 6

In this survey, the positive rate of Cat hair was $20.32 \%$, followed by Blattella germanica (19.62\%) and closely Dog hair (19.34\%). It demonstrated that animal hair and Cockroach were the most common indoor allergens except mites in Guangzhou. It was reported that the rate of sensitization to Dog hair was up to $42.08 \%$ in Foshan (Guangzhou's suburbs) probably due to lack of limitations for pet feeding there [22]. In addition, the 4 outdoor allergens were the least common allergic triggers. It was shown that only $7.16 \%$ subjects were reactive to the tested vegetal allergens, which was less than that of Beijing (10\%) [17]. These data fit well with the conclusion that the positive rate of outdoor allergens was higher in northern area than that of southern area [19]. Evidently such factors as region variation, climate and vegetation differences greatly affect the distribution of allergens.

The distribution between age groups indicated that sensitization to der.p., Cat hair and Blattella germanica was more common on school children rather than preschool children. Here are the analyses one by one: der.p. mainly exists in quilts, pillows and filer meshes of air conditioning, while der.f. was mostly found in grains, rice, noodles and grain dust. A survey conducted in Guangzhou showed that the number of der.p. was twice more than that of der.f. in the students' dormitories [23], so exposure to der.p. was more common for school children than preschool children, which obviously supported the conclusion from our study. Dogs are always kept more friendly towards people than cats. Younger children are always lack of safety judgments and self protection. To avoid them from the unexpected injuries, parents are more inclined to limit their contact with the cats. Probably that's why the positive rate of Cat hair was lower in preschool children group in this survey. Blattella germanica is a species of cockroach and it was reported that there were more cockroaches found in living room than in the bedrooms (71\%:54\%) [9]. As children grow up, they need less sleep time. Elder children would spend more time in living room, which increases the risk of being exposed to Blattella germanica. Accordingly, the positive rate of Blattella germanica was higher in school children in this study.

This study showed that there was no statistical difference on skin test reaction to Blattella germanica among season groups, while the distribution of the rest 10 allergens varied in seasons. There was no obvious change for the concentration level of indoor cockroach allergens in Guangzhou all the year round [9], which was consistent with our survey and revealed that Blattella germanica was a certain allergen for all seasons. The positive rate of dust mites was close in spring, summer and autumn, and it struck the bottom in winter. Besides, allergic sensitization to Tropical mites represented a highest frequency in autumn, while animal hair in winter, Alternaria tenuis and 4 outdoor allergens in both autumn and winter. Reaction to these 8 allergens all showed a lowest level in spring. Previous studies showed that the density of indoor dust mites in Southern China got to the lowest point in winter and reached the peak in autumn and summer $[9,24]$. We could then get the conclusion that meteorological conditions are considerably related to the seasonal variations of dust mites' distribution and the life style and living condition also have influences on that. In addition, fabric furniture was a specific risk factor that could lead to high concentration of dust mites in living rooms. Tailor-made mattresses and pillowcases could effectively reduce the risk of being exposed to the dust mites for children $[9,25]$. Therefore, we could suggest families with AR children to wash bedding more frequently in high-rate allergy seasons. Regular aeration by opening windows, reducing the usage of air conditioning and replacing the fabric furniture with leather furniture are also the helpful ways for allergen avoidance. Furthermore, parents can even offer special mattresses and pillowcases efficiently against mites to their children and provide them with masks when going out.

\section{Conclusion}

Most of the allergic rhinitis children all with positive SPT results in this study were reactive to at least two aeroallergens. Dust mites, Tropical mites and Cat hair were the most common allergens for AR children attending ENT outpatient clinic in Guangzhou City, Southern China. Blattella germanica was a certain allergen for all seasons. Dermatophagoides pteronyssinus, Cat hair and Blattella germanica were more likely to yielded positive skin test in school children. These allergens should be given the priority when making allergen avoidance strategies. Dust mites provoked strong positive reaction trend on AR children. We recommend early-stage specific immune therapy for a single mite to children rather than adults allergic to dust mites.

\section{References}

1. Asher MI, Montefort S, Björkstén B, Lai CK, Strachan DP, et al. (2006) Worldwide time trends in the prevalence of symptoms of asthma, allergic rhinoconjunctivitis, and eczema in childhood: ISAAC Phases One and Three repeat multicountry crosssectional surveys. Lancet 368: 733-743.

2. Kong WJ, Chen JJ, Zheng ZY, Shi QM, Zhou Y (2009) Prevalence of allergic rhinitis in 3-6-year-old children in Wuhan of China. ClinExp Allergy 39: 869-874.

3. Han DM, Zhang L, Huang D, Wu YF, Dong Z, et al. (2007) [Self-reported prevalence of allergic rhinitis in eleven cities in China]. ZhonghuaEr Bi Yan Hou Tou Jing Wai Ke ZaZhi 42: 378-384.

4. Subspecialty Group of Rhinology, Editorial Board of Chinese Journal of Otorhinolaryngology Head and Neck Surgery, Subspecialty Group of Rhinology and Pediatrics, Society of Otorhinolaryngology Head and Neck Surgery, Chinese Medical Association, Editorial Board of Chinese Journal of Pediatrics (2011) Guidelines for diagnosis and treatment of pediatric allergic rhinitis (2010, Chongqing). Zhonghua Er Ke Za Zhi 49: 116-117.

5. Mullol J, Valero A, Alobid I, Bartra J, Navarro AM, et al. (2008) Allergic Rhinitis and its Impact on Asthma update (ARIA 2008). The perspective from Spain. J InvestigAllergolClinImmunol 18: 327-334.

6. Bousquet PJ, Chatzi L, Jarvis D, Burney P (2008) Assessing skin prick tests reliability in ECRHS-I. Allergy 63: 341-346.

7. Guojian C, Qi L, Lipei P (2008) Investigation of house-dust mite fauna in school dormitory in Guangzhou City. Journal of Environment and Health 25: 229-231.

8. Zhu HM, Zhang YJ, Zhang WT, Su K, Shi H (2011) Variability analysis of allergic rhinitis related allergens in children. Chinese Journal of Otorhinolaryngology In Integrative Medicine 19: 339-342.

9. Zhang C, Gjesing B, Lai X, Li J, Spangfort MD, et al. (2011) Indoor allergen levels in Guangzhou city, southern China. Allergy 66: 186-191.

10. Sade K1, Roitman D, Kivity S (2010) Sensitization to Dermatophagoides, Blomiatropicalis, and other mites in atopic patients. J Asthma 47: 849-852.

11. Pi L, Liu HY, Liu YF, Guan QH, Zhang BD, et al. (2011) Distribution of common allergens and cross-reactivity of house dust mites and dust mites in 1136 children with allergic diseases in Guangzhou area. Journal of Clinical Pediatrics 29: 51-54.

12. Huang JH (2012) Housing difficulties of urban families and its determinants findings based on the survey in Guangdong. South China Population 27: 54-60.

13. XiaokatYB, Yan H (2008) Investigation on relationship between indoor air pollution and asthma in children. Endemic diseases bulletin 23: 3-5.

14. Chen YB, Jin YL, Li YH (2009) Impacts of high temperature on human health status in summer in different cities. Journal of Medical Research 38: 17-20.

15. Ling HS, Xie JC, Yang W (2010) Investigation and analysis into the indoor environment and energy concerning Beijing Urban Lifestyle. China population, resources and environment 20: 35-39.

16. Barnes KC (2000) Evidence for common genetic elements in allergic disease. J Allergy Clin Immunol 106: S192-200. 
Citation: Zhong J, Liu DB, Huang ZY, Zhong JW (2014) Skin Prick Test Reactivity to Aeroallergens in Allergic Rhinitis Children in Guangzhou, Southern China. J Allergy Ther 5: 178. doi:10.4172/2155-6121.1000178

Page 6 of 6

17. Wang C, Zhang L, Han D, Zhou B, Zhao Y, et al. (2006) [Prevalence of sensitization to aeroallergens in Beijing patients with allergic rhinitis]. Lin Chuang Er Bi Yan Hou Ke ZaZhi 20: 204-207.

18. Lü Y, Xie Z, Zhao S, Zhang H, Liu Y, et al. (2011) [Prevalence of allergens for Changsha patients with allergic rhinitis]. Lin Chung Er Bi Yan Hou Tou Jing Wai Ke ZaZhi 25: 491-494.

19. Li J, Sun B, Huang Y, Lin X, Zhao D, et al. (2009) A multicentre study assessing the prevalence of sensitizations in patients with asthma and/or rhinitis in China. Allergy 64: 1083-1092.

20. Arlian LG, Morgan MS, Vyszenski-Moher DL, Sharra D (2009) Cross-reactivity between storage and dust mites and between mites and shrimp. Exp Appl Acarol 47: 159-172.

21. Halloy JL (2004) [Sublingual hyposensitization]. Rev Med Brux 25: A256-258.
22. Kuang L, Feng HL, Mei XF (2010) Investigation of skin prick test on 1560 patients with allergic rhinitis in Foshan city of Guangdong Province, Journal of Clinical Otorhinolaryngology Head and Neck Surgery 24: 229-230.

23. Chen GJ, Lu Q, Pang LP, Chen XY, Shao JL, et al. (2008) Investigation of housedust mite fauna in school dormitory in Guangzhou city. Journal of Environment and Health 25: 229-231.

24. Fang ZJ, Cai YY, Wang LH (2000) The relationship between the density of dust mites in bedroom and attacks of asthma. Chinese Journal of Industrial Hygiene and Occupational Diseases 18: 350-352.

25. Halken S, Høst A, Niklassen U, Hansen LG, Nielsen F, et al. (2003) Effect of mattress and pillow encasings on children with asthma and house dust mite allergy. J Allergy Clin Immunol 111: 169-176. 